Made available courtesy of Alliance for Children and Families: http://alliance1.org/

***Reprinted with permission. No further reproduction is authorized without written permission from the Alliance for Children and Families. This version of the document is not the version of record. Figures and/or pictures may be missing from this format of the document.***

Educating professionals for practice in a multicultural society: Understandi...

Cathryne L Schmitz; Catherine Stakeman; Jose Sisneros

Families in Society; Nov/Dec 2001; 82, 6; Research Library

pg. 612

\title{
Educating Professionals for Practice in a Multicultural Society: Understanding Oppression and Valuing Diversity
}

\author{
by Cathryne L. Schmitz, Catherine Stakeman, \& Jose Sisneros
}

\begin{abstract}
The United States is a society diverse in culture, race, ethnicity, religion, and income; one struggling with a past involving oppression, inequality, and buried knowledge. In order to heal and strengthen, we must educate ourselves about the many strands of our history; grow to appreciate and enjoy the multiple cultures, races, and realities; and recognize the consequences of current and historical oppression. Social work professionals can and should play a lead role. Social work educators can provide leadership in developing learning opportunities with parallel foci on the history and impact of oppression, and the strength and joy of diversity. After a review of the issues, a model is presented for guiding/facilitating this early learning.
\end{abstract}

THE UNITED STATES IS A MULTICULTURAL, pluralistic society, challenged from its inception to educate for and about diversity. The immigration of Western Europeans from many cultures to a land already occupied by multiple Native American cultures required accommodation and assimilation in norms, language, and values (Takaki, 1993; Zinn, 1980). English was chosen as the national language by the colonial leadership and immigrants learned it at the expense of their own language and culture. Traditionally, the history ("his story") of the United States has been written from the European (male) perspective (Beard, 1995; Chomsky, 1993; Taka$\mathrm{ki}, 1993$ ). Facts have been omitted or distorted about the displacement of Native Americans, the alternating immigration and enslavement of Africans, the relationship with Latinos including the migration and displacement of Mexicans, and the bringing in of a labor force from China and Japan followed by the immigration of other Asians, Southeast Asians, and Pacific Islanders (Takaki, 1933; Zinn, 1980).

The major institutions (government, schools, social welfare, banking, business) have been heavily influenced by western European, White Anglo-Saxon traditions and mores (Gollnick \& Chinn, 1990). The increase in non-European populations and the dissatisfaction of people of color, women, gays and lesbians, the elderly, and people with disabilities, are bringing new demands for equity in education and employment, and an overall voice for change in institutional values
(Beard, 1995). The various social movements espousing equity and equality intersect and must coalesce for true equity and lasting change.

Currently, there is much discussion about multicultural education, particularly in fieids such as social work and education. Many books exist on cross-cultural practice in the human service fields (Almeida, 1994; Ewalt, Freeman, Kirk, \& Poole, 1996; Greene, 1999; Iglehart \& Becerra, 1995; Kavanagh \& Kennedy, 1992; Lum, 1996, 1999; Paniagua, 1994; Philleo \& Brisbane, 1995; Ridley, 1995). Unless practitioners are brought through a process that helps them understand the impact of oppression and the value of diversity, however, they will not have a context for the integration and application of this material.

While a number of books exist on educating for a multicultural society (Fiol-Matta \& Chamberlain, 1994; Geismar \& Nicoleau, 1993; Hidalgo, McDowell, \& Siddle, 1990; Roberts, Gonzales, Harris, Huff, Johns, Lou, \& Scott, 1994; Schoem, Frankel, Zúñiga, \& Lewis, 1995), there is little concrete information to guide preparation of social work professionals and students for multicultural practice. The potential for diversity as a source of strength and joy frequently goes unvoiced. As Sue (1994) stated, "Personal and cultural values are challenged by diversity ... we must develop a positive appreciation for diversity and multiculturalism, valuing human diversity and realizing that it is an essential part of existence" (p. 2).

Families in Society: The Journal of Contemporary Human Services

Copyright 2001 Families International, Inc. 
Experience has taught us that movement toward informed practice in a multicultural society involves three levels or stages of learning. The first level is multidimensional. At this level, parallel knowledge is presented simultaneously on the many histories and cultures of the United States, and the history and impact of oppression. Exposure to the new knowledge through a process encouraging the development of critical thinking skills helps learners examine the identity and beliefs of self and others. The second level involves engaging learners in a dialogue that helps them discuss and learn across the boundaries of difference. After these two levels participants are able to move to the third level, learning about social work practice in a multicultural environment. It is at this point that students can learn from the body of literature on multi/cross-cultural practice. The concepts, knowledge, and skills that support "cultural competence" (for definitions and discussions see Carter, 1995; Leigh, 1998; Lum, 1999; Green, 1999) and "ethnic sensitive practice" (for definitions and discussion see Devore \& Schlesinger, 1998; Green; Lum) are more meaningful and can be incorporated with increased understanding at this juncture of the learning process.

Through this article, a model is presented that has been effective in helping social work students move into the first two levels of learning to begin the lifelong journey toward growth, inclusion, and exploration. Experience in and knowledge about educating on the complex issues of diversity and oppression is shared. Analysis of student projects and evaluations have informed the development and refinement of the model. The multicultural curriculum described has been taught by faculty diverse in race/ethnicity, gender, and sexual orientation. This process of inclusive learning has been successful in engaging students at four universities during 5 years, and in three regions.

\section{Reality, Learning, and Resistance}

Because social work professionals and students come with a range of values, cultural histories, and prejudices, educating on the impact of oppression and the value of diversity can be like walking through a minefield. Participants not only respond out of unexamined values but also out of the defensiveness born of guilt and shame and/or the anger born of pain (see Garcia \& Van Soest, 1997, and Lather, 1992 for related discussion). Educators must learn to bring participants carefully through multiple emotions into a place of accepting and understanding our societal history of oppression by race, gender, socioeconomic status, and sexual orientation.

Recent articles (Garcia \& Van Soest, 1997; Millstein, 1997) analyze some of the barriers to the early stages in this process and the pivotal role of self-reflection. Garcia and Van Soest examine the resistance experienced in facilitating student learning about racial diversity and oppression. They identify the importance of moving students through a self-reflective, critical process. Millstein as well as Garcia and Van Soest describe the use of a taping project that engages each student in self-monitored learning and reflection on power and inequality. This project is a valuable tool supporting a self-informed educational process. These studies support the importance of interweaving process and knowledge building.

A framework does not exist, however, for guidance in the development of curriculum on multicultural social work, which is broader and more inclusive. The multicultural perspective has the potential to be inclusive, recognizing the multiple cultures of the United States (Fellin, 2000). The inclusiveness has both the potential to reflect the rapidly changing cultural environment of the country (Fellin) and to bring more participants into the dialog across multiple contexts of oppression and privilege. While there are many views on multiculturalism, we have chosen to build from the concepts of critical multiculturalism (Kincheloe \& Steinberg, 1997). Within critical multiculturalism, class, power, and domination are central to analysis and knowledge building. Engaging the critical perspective promotes individual consciousness raising about how and why one's political opinions, socioeconomic class, role, religious beliefs, gender role, and racial self-image are shaped by the dominant perspective.

Expecting and understanding resistance, educating to listen and question, opens a space for exploring oppression with its multiple realities and faces racism, sexism, homophobia/heterosexism, classism, religious discrimination, and difference. It is difficult, however, to acknowledge racism, inequality, oppression, privilege, and stereotypes. Elizabeth Ellsworth's (1989) study of the pedagogy of antiracist education reflects numerous sources of fear in student resistance including vulnerability, misunderstanding, history and memories, guilt, and resentment. Tatum (1992) identifies three sources of resistance to learning: (a) race as a taboo topic in mixed settings, (b) the belief in the United States as a just society, and (c) the denial of personal prejudice.

Learning is a process (Goldstein, 2001) inclusive of resistance with learners experiencing a multiplicity of contradictory reflections on knowledge. Because attitudes, values, and behaviors are embedded through socialization, a process designed to shift worldview threatens self-identity, precipitating the surfacing of resistance. Lather (1991) provides a framework for understanding the process of resistance and learning. Based on her study of student response to feminist consciousness-raising, Lather developed a model to exempli- 
fy the learning process, which is expanded in Figure 1. When confronted with the reality of oppression, learners either accept or reject early in the process. Unless participants are able to accept the reality of oppression and are helped to separate the ugliness of oppression from the beauty and strength of diversity, they are not able to embrace and enjoy diversity. If they accept the reality of oppression, the educator must take

Figure 1. The learning process.

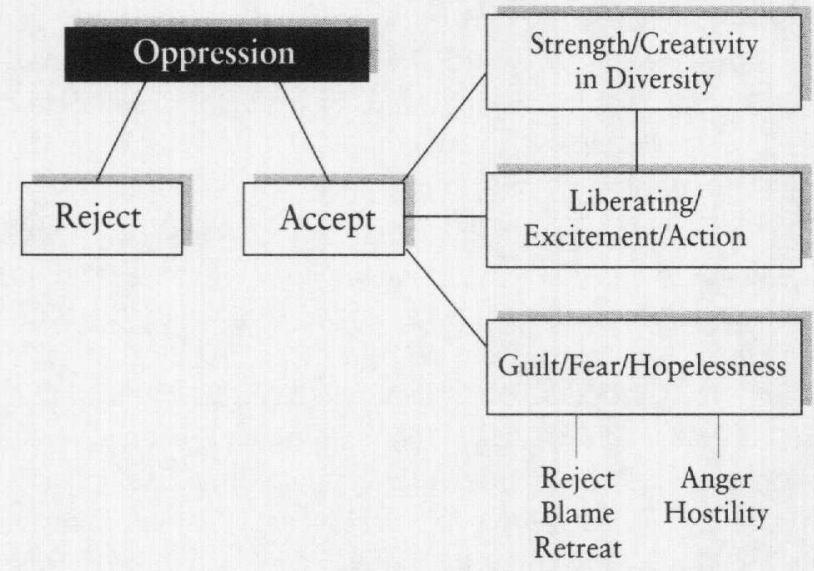

Note: Based on Lather (1992, p. 127).

care to help students move past guilt, fear, hopelessness, anger, and/or blame into excitement, learning, and action.

The process itself is important. Garcia and Van Soest's (1997) study supports the importance of educating beyond the cognitive level to student "examination of societal oppression in their own lives" (p. 128). The multicultural teacher "strives to encourage the development of a critical consciousness" (Lewis, 1995, p. 27), one that remains open to transformation and interaction. This requires the educator to be "participating in the learning experience, by continually reflecting on what students are learning ... and by constantly seeking alternative methods of presenting material" (p. 27).

A guided, supportive learning process helps students come to the place of discovering a joy in learning about diversity and an anger at lack of knowledge. With careful planning and thoughtful timing, participants are able to move through their resistance to embrace the content, process, and activities (see Goldstein, 2001, for a discussion of the tension of the learning process). While some students become more open to learning about diversity, others remain reluctant to risk without strong, supportive role models. Our experience indicates that diversity among educators and a willingness to discuss race and oppression from their own experience with discrimination and prejudice helps participants enter the dialogue. They are more willing to share their struggles with these issues if the educator is willing to share attempts to work with personal biases, stereotypes, anger, and guilt.

\section{Focusing the Process/Shifting Perception}

Relying on the premise that reality is socially constructed (Berger \& Luckmann, 1966), the practice of social work is based on the search for "meaning construction" (Scott, 1989). The constructivist approach supports the education of social work students on self, culture, and help-seeking behavior (Lee \& Greene, 1999). It is within the context of our history of interactions with others, family mythology, language, culture, and experience of power and control that we interpret our current context. Culture involves an integrated pattern of behavior, norms, beliefs, values, and skills arising from ones racial, ethnic, religious, and social groups (Sue et al., 1998; Lum, 1999). The contextual interactions are complex and intertwined. Most, if not all of us, have experienced some form of prejudice, discrimination, and/or hardship while also knowingly or unknowingly participating in maintaining racism, sexism, classism, and heterosexism even if only through inaction. "The dialogue on culture and self bridges the more abstract intellectual discussion and students' personal experiences, thus facilitating a reflexive learning process" (Lee \& Greene, p. 34).

While blame, fault, and guilt arise as part of the discovery, a focus on moving beyond these feelings toward reflection and growth facilitates a new social consciousness. As framed by Millstein (1997), "A major focus is to ... help students engage in critical self-reflection" (p. 493). Many learners want to withdraw from discussion, exercises, and reading due to powerful feelings. The withdrawal is further heightened in a multicultural environment. Anger and guilt can result in participants responding negatively to one another. A multi-racial teaching team can model constructive dialog across difference.

Resistance to knowledge building is not only individual but also family and community. A major barrier to learning is a lack of personal understanding of one's culture, socialization, and social structure. There is an "invisibility" of privilege in being White. When one is White, one simply does not think about it (Lopez, 1996). White students frequently do not know about White culture or White privilege and therefore resist the notion that students of color may experience oppression. Students of color are often painfully aware and carry pain and/or anger into the discussion. The pervasive social denial of personal prejudice and lack of knowledge about the impact of racism on self and others produces potential barriers. Because race is a taboo topic for discussion (Tatum, 
1992), even as individuals begin to open up, they face pressure from family and friends to remain silent. Additionally, the community at large prides itself on believing that the United States is a just society. This, in part, stems from cultural mores heavily influenced by a confusing and conflictual mix of religious, cultural, and gender socialization.

Understanding that oppressions overlap facilitates openness as students find a place to enter the discussion through linking mechanisms. While the manifestations of oppression vary, there are common themes that desensitize otherwise compassionate people to oppressive structures and actions. Many great minds have drawn the link across sour common existence. Martin Niemoeller's poem (as cited in Bartlett, 1992) written in response to Nazi Germany helps set the tone:

\begin{abstract}
In Germany they came first for the Communists, and I didn't speak up because I wasn't a Communist. Then they came for the Jews, and I didn't speak up because I wasn't a Jew: Then they came for the trade unionists, and I didn't speak up because I wasn't a trade unionist. Then they came for the Catholics, and I didn't speak up because I was a Protestant. Then thev came for me, and by that time no one was left to speak up. (p. 684)
\end{abstract}

Other visionary leaders such as Martin Luther King, Jr. (1990) have seen the connection as reflected in his statement "An injustice anywhere is a threat to justice everywhere" (p. 172). Audre Lorde (Gordon, 1983) draws similar parallels in her poem There is no hierarchy of oppressions. The context is deepened by presenting historical information on inequality/inequity, poverty, and the nature of population shifts. Stories and articles (e.g., Abramovitz, 1995; LaVelle, 1995; Meyer, 1994; Nichols-Casebolt, Krysik, \& HermannCurrie, 1994; The war against woman, 1994; Starrels, Bould, \& Nicholas, 1994; van Wormer, 1994), videos, and presentations on the global nature of the oppression of women, persons of color, and persons in poverty bring the discussion to life for learners.

Excitement is generated and knowledge gained through the interspersing of discussion and small group exercises with articles on the culture and history of major non-European racial and ethnic groups as well as women, gay men, and lesbians. Growing awareness of the significant contributions of many groups (Native Americans, African Americans, Asian Americans, Latinos, women, gays, and lesbians) to the building of this nation challenges students to explore and learn as they grasp the shallowness of their knowledge of history. From a position of valuing the strengths, talents, and perspectives of individuals from diverse cultural backgrounds, they begin to learn the need to examine internal and external barriers to accessing these strengths.

\section{Establishing the Environment}

The multicultural teaching of oppression and diversity can only occur in a safe, trusting environment (Beard, 1995; Garcia \& Van Soest, 1997). This space is built within the context of respect, openness, patience, energy, sensitivity, and excitement. Faculty enthusiasm about the value of multiculturality sets the tone. Faculty establish a legitimacy for the discussion by acknowledging and normalizing the pervasiveness and dehumanizing impact of racism, sexism, classism, and homophobia/heterosexism. A balance between educating about diversity and facilitating an understanding of oppression and its impact is anchored in several underlying premises. Table 1 provides an outline of the premises surfacing through reflection on the literature reviewed above. These premises provide a framework for curriculum development and implementation. They ground the process, guiding the choice of activities, readings, and discussion. This framework structures a context that supports student growth in the ability to recognize and analyze the destructiveness of oppression, learn the joy in expanded knowledge, and assess rhetoric and symbols.

Table 1. Underlying Premises

1. All "isms" are based upon social constructions.

They are reinforced by institutional power, economic power, and educational systems.

"Isms" are internalized and reinforced by family, friends, and neighbors.

2. Understanding historical roots and current rationale allows the opportunity for change.

Participants see who loses and who gains by historical and current rationales for inequity.

3. There is no hierarchy of "isms."

If you can oppress one group of people, you can oppress all and establish boundary mechanisms to keep oppressions intact.

4. There is tremendous power in controlling the framing of the dialogue, the language of the dialogue, and the symbolism associated with the dialogue.

Reframing allows greater freedom of dialogue and the interconnecting of ideas.

Understanding the commonalties of pitting groups against one another, through the fostering of fear and ignorance, facilitates the building of bridges across groups. 
Symbolic language patterns frame the construction of "social reality" (Searle, 1995) establishing the social and political dialogue that maintains some groups in a privileged position (related discussion in Garcia \& Van Soest, 1997). Analysis of the connections across symbols, language, and power is enlightening; informing discussion on the significance of reclaiming language symbols. Participants are challenged to look to themselves, others, and previously unknown written and oral histories for the answers. A basic set of goals (Table 2), flowing from the premises, frames choices and structure, providing a foundation for design, implementation, and evaluation.

\section{Table 2. Teaching Goals}

- Increase understanding of internalized and institutional oppression.

- Educate about the value of multiculturality and the strength of diversity.

- Provide material on the negative impacts of oppression on the oppressed and the oppressor.

- Increase student awareness about the impact of oppression on their lives

- Help students identify the privilege of male gender, White skin, and heterosexual orientation.

- Expand knowledge of multiracial, multicultural, and multigendered history locally, nationally, and globally.

- Provide exposure to multiple cultures and worldviews.

- Facilitate the development of critically thinking skills.

- Create the possibility for students to work together toward a more just society.

These goals, combined with core process techniques (Table 3), inform curriculum development. A safe learning space structured around interaction, discussion, and knowledge building encourages exploration and growth. Effective models engage participants in active learning, teaching the skills for critical thinking. Faculty and peer patience with, and respect for, each individual's process facilitates change rather than resistance. Faculty use of self provides a model for discourse on difference, internalized oppression, and racism, sexism, classism, and heterosexism. The timing and pacing of presentation, reflection, activities, and discussion are key factors. Education about the use of terms and symbols impacts the learning and thinking processes. For example, to refer to a woman as a girl implies a lack of adult status. Negative language in regard to race, ethnicity, class, and sexual orientation are intolerable because it implies a lesser status. A commitment to anti- racism/sexism requires monitoring common language patterns for overtones of racism and sexism such as referring to black as negative and white as positive.

Table 3. Process Techniques

Awareness and use of pacing and patience

Attention to vocabulary, language, and symbol

Creative knowledge presentation

Productive interaction grounded in common definitions and agreed-upon ground rules

Active learning process

Cohesion building through group process

Educator self-awareness and comfort with strong emotions; use of self

Precipitation and modeling of action

Ground rules. In order to discuss oppression and prejudice, faculty and students together develop a set of behaviors, which provides a framework for the development of safety and trust. Ground rules establish the norms for participation. Respecting current participant knowledge and worldview recognizes learning as a process-knowledge and truth as constructed and contextual, and embarrassment and ignorance as inevitable possibilities. Basic rules include confidentiality, mutual respect, required attendance, and speaking for self only with the use of "I" statements. An environment safe for risk taking means that what is said in the learning environment is treated with civility and remains private. Rules are established for valuing feelings and confusion. Criticism and insult are not acceptable and participants may request a time-out with an agreed-upon hand signal when their feelings are hurt, they are angered, or they are embarrassed and confused. Participants learn to approach each other respectfully and individually rather than through assumptions and generalizations, allowing the emotional space needed to avoid withdrawal into familiar defense postures. As one participant noted, "It is important to keep class safe, so that we can own our ideas and not just be fed information... Keep class interactive and open to hear anything."

Setting the stage. As an entry into the process, each participant is asked to list one thing they like about their gender and one thing they like about their race/ethnicity. This exercise provides a focus on self and helps the learner orient to the issues from a personal perspective. Women can have difficulty listing a positive about their gender and White participants commonly are at a loss to discuss a positive about their race, not having frequently thought about their own race and 
Table 4. Matrix of Oppression

\begin{tabular}{lcccccc}
\hline Race/Ethnicity & Gender & Class & Sexuality & Education & Ability & Religion \\
\hline Anglo & Male & Ruling & Heterosexual & Higher & Able-bodied & Christian \\
Other & Female & Working & Gay, Lesbian, Bi & & Other & \\
\hline
\end{tabular}

Note: Other potential categories: language, age.

culture. If they have, their knowledge may bring guilt, which interferes with learning. This exercise begins a process of self-growth and heightened awareness.

Experience has led to knowing the value of educating students on the interlocking web of oppression across multiple dimensions including race, gender, sexual orientation, religion, education, ability, nationality, and age. Conceptually, learners often lack an understanding of the structural difference in power relations. The matrix presented in Table 4 serves several functions. This model provides a framework for examining the interplay between institutional and internalized oppression while allowing participants to identify themselves in two dimensions-oppressed and privileged. The process helps decrease resistance. Separating institutional oppression and internalized oppression helps learners identify the dynamics and impact of racism, sexism, classism, religious oppressions, and heterosexism on all members of society. Participants begin to analyze personal and social mechanisms for maintaining oppression and privilege, contextualizing their own areas of privilege and role in oppression. Subsequent discussion facilitates the examination of how we each participate (frequently unknowingly) in the oppression of others based on our privileges. Participants begin to grasp the concept that when groups are singled out by race, gender, disability, income, sexual orientation, religion, and culture, the behaviors of groups with more power impact adversely on groups with less power through unequal access to resources.

Defining terms. Terms like racism, prejudice, privilege, power, and oppression are defined and discussed so all participants possess a collective meaning of the terms and concepts. The two hardest terms to get consensus on are racism and privilege. Racism is defined as a structural issue. Persons of color in the United States, by definition, cannot be racist because they lack the power to discriminate systematically and economically. Persons of any racial/ethnic group, however, can be prejudiced and biased, dimensions that encompass personal attitude and action. This discussion allows for confusion but moves toward a consensual understanding of the concepts.

Privilege is defined as unearned advantage. Initially, White participants generally have problems with this definition. They are aware that they have worked hard for their achievements and don't understand how they could be perceived as having privilege. Articles by Peggy McIntosh (1992,1989) on male privilege and race privilege facilitate an understanding of the labels and the issues. By reviewing the advantages of males, then reflecting on her own advantages, McIntosh was able to recognize her privileged position by race. This is a turning point for many White learners, helping them understand the privileges garnered from being White in the United States Lopez (1996) provides a history and analysis of the legal construction of race in the United States Students are shocked by the defining of Whiteness in law and the policy and personal implications. The curriculum expands the discussion to other privileges some or all of us share because of education, socioeconomic status, disability, sexual orientation, and/or religion.

\section{Texts, Videos, and Resources}

Articles, short stories/narratives, videos, and speakers reflect difference and similarity; diversity and oppression. Most of us struggle with identity crises as well as some form of difference or diversity; and, unfortunately, no group is immune from abuse amongst its own members. Oppression by culture, race/ethnicity, gender, income, religion, language, and sexual orientation add diverse layers of adversity and barriers to social, political, and economic opportunity. Persons from oppressed groups struggle against feelings of oppression and the domination and sense of helplessness that inequality engenders. Racism and sexism add barriers to the ability to compete equitably, impeding the chance to succeed without structural safeguards. Teaching aids deepen knowledge of these issues (Table 5), helping participants evaluate the adversity layers of oppression add to personal struggles.

Articles and books enrich the process when they provide knowledge about the history and richness of diverse groups, incorporating models of privilege, identity development, and anti-oppression and anti-racism. The integration of current issues and articles from newspapers, other media, and conferences infuses vibrancy into the discussions reminding students that these are not old issues. Analysis of international ethnic struggles is another means. The discussion shifts the prism for cultural reflection as participants analyze micro and macro expressions of oppression without a sense of national guilt or responsibility. 
Table 5. Resources

Textbooks

Leigh, J. W. (1998). Communicating for cultural competence. Boston, MA: Allyn \& Bacon.

Rothenberg, P. S. (1998). Race, class, and gender in the United States: An integrated study. New York: St. Martin's Press.

Targeted Reading

Pharr (1988, 1993)

Tatum $(1992,1994)$

Models

Black identity development: Cross (1971, 1978)

White antiracists: Helms, P. (1990); Tatum (1994)

White privilege: McIntosh (1989, 1993); Winter (1977)

Videos

Asianization of America, The (1988)

Biculturalism and acculturation among Latinos (1991)

Black Is, Black Ain't (Riggs, 1995)

Eyes on the Prize (Blackside, Inc., 1993)

Honour of All (Lucas et al., 1985)

In the Whiteman's Image (Lesiak, 1991)

Martin Luther King: Legacy of a Dream (Kaplan, 1989)

Sarafina (Singh, 1992)

Schindler's List (Spielberg, 1994)

Skin Deep (Reid, 1995)

We Are Family (Sands \& Banks, 1987)

Poems and Other Readings

Lorde, A. (Gordon, 1983; Lorde, 1984)

Niemoeller, M. (Bartlett, 1992)

Activities, novels, ethnographies, and narratives bring life to the issues and personalize the stories. Based on new understandings, participants enjoy audiovisual presentations designed to expand knowledge and exposure. Learners are further surprised by exercises exposing their own multicultural knowledge and attitudes. Leigh (1998) is a good text for introducing social work students to a model for listening and learning with cultural competence. It provides a framework for interviewing and assessing, which is embedded in cultural awareness. By performing an ethnographic interview, students discover perspectives previously hidden from their view. Individuals interview a member of any racial group other than their own. The interview involves questions surrounding culture, language, frame of reference, family, aspirations, vision, and community. The taping project described by Millstein (1997) and Garcia and Van Soest
(1997) encourages student reflection with evaluation of their own change process.

\section{Diversity Among Faculty}

While there is no literature on the significance faculty diversity, our own observation, experience, and analysis of student evaluations indicate that the learning process is ideally facilitated by a racially/ethnically diverse team. While educators of color are vital to and pivotal in the education of individuals of all colors, White educators also have a role and responsibility for teaching diversity and oppression. Instructor discussion about and across race models a process; a discussion all social work professionals engage in for practice in a multicultural society. If not team-taught, carefully chosen speakers add diversity while modeling openness and self-exploration.

Information related by faculty of one color/ethnicity may be heard differently by some learners when repeated by educators of another color/ethnicity. White participants can have difficulty hearing the material without guilt and can be especially critical of faculty of color. Participants of color can have similar problems with discussion and knowledge based on the input/direction of White educators. Black educators help Black learners integrate a theoretical and historical perspective with strong feelings based on experience. This observation is supported by similar findings of Garcia and Van Soest (1997). Although White participants struggle with internalized guilt in order to learn about oppression from educators of color, the growth is liberating.

Targeted or integrated: The false discussion. Education and practice for a multicultural society are at the core of our profession. The Handbook on Accreditation Standards and Procedures (1994) by the Council on Social Work Education, and the National Association of Social Workers' Code of Ethics (1996) hold this principle as central. Whether students learn the context for multicultural practice through a separate social work course or infused within core social work curriculum is not the most important issue. There is no research to support additional benefits through infusion versus separation (Reynolds, 1995). What matters is that students do learn the material; that this goal is a primary goal of the curriculum. The tendency in social work education is to combine the separate and integrated education (LeDoux \& Montalvo, 1999). A separate course followed by integrated curriculum places the dialog at the center of student learning. The introductory course facilitates movement through the first two levels of learning - self-awareness, cultural knowledge building, understanding oppression, and cross-cultural dialogue. Integration across the curriculum is then required to teach the skills of multicultural practice and culturally sensitive knowledge building, the third level of learning. 


\section{Implementing the Model}

Experience has been an educator; students the teachers. Initially, resistance-expressed through negativity, closed body language and facial expressions, and journal/evaluation comments-was strong and quick. Student evaluations reflected anger but lacked specific feedback. Evaluations with increasing specificity led to an understanding of the basis for withdrawal into guilt, shame, fear, pain, and anger. This early feedback led to the development of the model described.

The curriculum components have been taught through integration as well as a separate course. The course of study was designed to bring the students through the first two levels or stages of learning. Process was engaged for self-reflection, the analysis of the impact of oppression and privilege, and knowledge building on diverse cultures, gender, and sexual orientation.

Dialog on the impact of oppression and the value and strength of diversity was interwoven within the educational process. In the classroom, students explored the issues together, educating one another. Multicultural historical information was provided along with a knowledge base about many of the cultures contributing to the historical and social context of this nation. Professional as well as current newspaper articles were shared for analysis; videos (frequently popular videos) enriched the process, precipitating discussion and reflection. When teaching students about leadership and social action, a video on Martin Luther King Jr. was shown. Many of the students knew little about him and were amazed at his skills, presence, impact, and power.

Current and historical information on oppression internationally enriched the discussion. The discussion of the context of oppression that allowed the development of Nazi Germany, Japanese internment in the United States during World War II, South African apartheid, and the more recent conflicts in nations such as Bosnia, Somalia, and Rwanda facilitated the development of critical thinking skills. Videos such as Sarafina set a stage for understanding the impact of unequal power on both the oppressed and the privileged. This video provided the opportunity to observe the value and strength of diversity and the evil of oppression slightly removed from the culture/society of the participants. Understanding oppression outside self helped remove the guilt factor. Reflection and discussion precipitated the transportation of that knowledge back to the participants' own cultural context(s).

Through reflective journals, students shared issues with the instructor that they were unwilling to address openly with classmates. The instructor responded with personalized comments and suggestions. The interactive process allowed a more personal and private struggle. Each week, students analyzed the readings, videos, classroom activities/discussion, and their own history and knowledge. Students shared their concerns, fears, anger, and joy, providing faculty with a sense of student integration, knowledge building, and misperceptions or difficulties.

Evaluations reflected an overwhelmingly positive response. Students were asked on a qualitative evaluation to respond to the question, "Do you feel this course helped increase your knowledge of the issues of diversity and your understanding of oppression?" Over six semesters, 164 of 176 students responded. The vast majority $(91 \%, 150$ students) was very positive. Ten of the others were ambivalent indicating they learned some or a little. Only $2 \%$ were negative about the diversity content.

Evaluations evidenced not only increased knowledge but also an appreciation of the growing awareness and its importance (see Table 6 for representative evaluative comments). Participants developed an excitement about their growth as the wealth of diversity in the United States became more apparent. One of the students reflected on the feeling, "I really did feel like every class helped to make me a better person. The stereotypes are slowly being destroyed." Participants indicated an appreciation of the opportunity to examine personal and societal values and norms that impact all players in a multicultural society. As one students stated, "I am much more aware of multicultural issues and have become more sensitive to oppression." Further, many expressed frustration at not being exposed to this knowledge sooner. These changes have ripple effects as reflected in student comments such as, "[The course] affected interactions with my family."

\section{Discussion and Conclusion}

At the core of our national struggle is the incorporation of diversity. At the center of our profession is the value of multicultural knowledge. Culturally competent practice builds from self-awareness of ones values, beliefs, and racial/ethnic identity. From this base, one can develop the skills for multicultural practice (Carter, 1995; Leigh, 1998; Lum, 1999; Green, 1999), A major challenge for us as educators and professionals is to participate in and lead critically thoughtful discussions about difference. As Anderson and Hill Collins (1998) state "The strength and richness of our society lies in its diversity, but that potential ... will only be realized through social structures that value and protect all human experiences" (p. 19). The shift begins "by valuing the experiences of those ... excluded and questioning the assumptions made by all groups" (p. 17).

The model presented begins this process. It is a model developed through years of experience growing and shifting 
Table 6. Themes From Participant Evaluations

Themes

Comments

Value of the course

- I am more aware of the value of diversity and the realism of oppression.

- This class helped me understand that oppression comes in all forms and must be dealt with if we are ever going to live in a just society.

- It helped me to more fully understand the importance and the need for practitioners to be open-minded about situations.

- It recharged my desire to fight inequality-I'm now thinking a lot. My eyes are much more open.

Knowledge building

- This course helped me increase my knowledge of the issues of multiculturalism and my under standing of oppression.

- I do not think I could possibly give a concise enough answer in this little space about all I have learned in this course about diversity and oppression.

- This course introduced me to many ways of understanding oppression. It proved to be a great awaking to me.

- The class on oppression was extremely helpful in understanding the costs of oppression to all.

- The course expanded my knowledge of oppression to include all forms and kinds, not just racial.

- The most significant thing I learned was the idea of systemic racism ... I never thought of racism as systemic, rather I focused on individuals who I perceived as racist.

- I realized that acknowledging cultural differences is not discrimination. The fact is that there are differences and this is what makes the country great.

Growing awareness

- I am learning to look harder.

- We cannot learn to look at one problem in isolation.

- I am more aware of cultural norms and values.

- [The course] forced me to surface some of my prejudices. It gave me a broader view of oppression-a key part of the course.

- I am more aware.

- I didn't understand oppression before.

- I learned about myself and how I'm viewed.

- I gained insight into ways people are oppressed and oppress themselves.

- [The course] made me think about oppression in the world and around me.

- By making me aware of the realities of our society I feel I have a better understanding of oppression and the effects of it.

with direct and indirect student feedback. It focuses heavily on helping students move into the learning process; through the early stages of dialogue and knowledge building. As framed in one evaluative comment:

In order to understand the issues of multiculturalism and oppression, one must understand how each group is affected by it. Being able to view another position in society and how it may affect their behaviors, values, and ideas is important. (Student)
Space for nurturing cross-race discussion as well as expanded learning about race/ethnicity, culture, class, gender, sexuality, disability, and religious difference form a basis for informed practice in our multicultural society (see Fellin, 2000 for related discussion). Learners begin to understand that oppression impacts the oppressed and the oppressor. Students express excitement about learning: "The best course I ever had," "This course encouraged me to look at my values," "I learned a lot."

Important themes have emerged. Instructor use of "I" language and personal examples models and normalizes on- 
going struggles with racism, sexism, classism, and homophobia/heterosexism. Respecting participant process and history, timing and pacing of the material, setting ground rules, and careful selection of text/readings and exercises are basic components in determining success or failure of these early learning phases. In line with Lewis's (1995) insight, "Instead of merely presenting new information, we explore together the importance of their current levels of knowledge" (p. 31). Videos, reflection with feedback, discussion, and modeling expand learning. Written journal entries provide evidence of participant ability to synthesize and integrate the material; supporting self-reflection and growth while contributing to the development of a dialogue between the learner and the educator. Involving persons of many colors/ethnicities, both genders, and differing sexual orientations helps learners engage in inclusive dialogue.

Multicultural practice is based on "increasing our ways of knowing ... enabling us to reread ... a particular meaning and uncovering new meanings ... perspectives that we could not previously see" (Schoem et al., 1995, p. 283). Growth requires respect for the anti-racist and anti-sexist work of women and men of all colors. As social workers, we strive to amplify the voice of the silenced and challenge oppressive structures. This "requires a reconstruction of knowledge so that we have some basis from which to change these damaging and dehumanizing systems of oppression" (Andersen \& Hill Collins, 1998, p. 14).

\section{References}

Abramovitz, M. (1995, May/June). Welfare and women's lives: Toward a feminist understanding of the reform debate. Democratic Left. 5-8.

Almeida, R. V. (Ed.). (1994). Expansions of feminist family theory through diversity. New York: The Haworth Press.

Andersen, M. L., \& Hill Collins, P. (1998). Race, class and gender: An anthology. Belmont, CA: Wadsworth Publishing Company.

Asianization of America, The [Video]. (1988). (Available from Films for the Humanities \& Sciences, P.O. Box 2053, Princeton, NJ 08543)

Bartlett. J. (1992). Bartlett's familiar quotations (16 ${ }^{\text {th }} \mathrm{ed}$.). Boston: Little, Brown \& Co.

Beard, V. H. (1995). Developing and teaching an undergraduate course of multicuitural education. Paper presented at the Twelfth Annual Teachers College Winter Roundtable on Cross-Cultural Psychology and Education, New York.

Berger, P. L., \& Luckmann, T. (1966). The social construction of reality: A treatise in the sociology of knowledge. New York: Doubleday \& Company, Inc.

Biculturalism and acculturation anong Latinos [Video]. (1991). (Available from Films for the Humanities \& Sciences, P.O. Box 2053, Princeton, NJ 08543)

Blackside, Inc. \& New Learning Projects, Inc. (Co-Producers). (1993). Eyes on the prize [Video]. (Available from PB Service, 1320 Braddock Place, Alexandria, VA 22314)

Carter, R. T. (1995). The influence of race and racial identity in psychotherapy. New York: John Wiley \& Sons.
Chomsky, N. (1993). Year 501: The conquest continues. Boston: South End Press.

Council on Social Work Education Commission on Accreditation. (1994). Handbook on accreditation standards and procedures (4th ed.). Washington, DC: Council on Social Work Education.

Cross, W. E., Jr. (1971). The Negro to Black conversion experience: Toward a psychology of Black liberation. Black World, 20 (9), 13-27.

Cross, W. E., Jr. (1978). The Cross and Thomas models of psychological nigrescence. Joumal of Black Psychology, 5 (1), 13-19.

Devore, W., \& Schlesinger, E. G. (1998). Ethnic-sensitive social work practice ( $5^{\text {th }}$ ed.). Boston: Allyn \& Bacon.

Ellsworth, E. (1989). Why doesn't this feel empowering? Working through the repressive myths of critical pedagogy. Harvard Educational Review, 59, 297-324.

Ewalt, P. L., Freeman, E. M., Kirk, S. A., \& Poole, D. L. (1996). Multicultural issues in social work, Washington, DC: NASW Press.

Fellin, P. (2000). Revisiting multiculturalism in social work. Journal of Social Work Education, 36, 261-278.

Fiol-Matta, L. \& Chamberlain, M. K. (1994). Women of color and the multicultural curriculum: Transforming the college classroom. New York: The Feminist Press.

Garcia, B., \& Van Soest, D. (1997). Changing perceptions of diversity and oppression: MSW students discuss the effects of a required course. Journal of Social Work Education, 33, 119-129.

Geismar, K., \& Nicoleau, G. (Eds.). (1993). Teaching for change: Addressing issues of difference in the college classroom. Cambridge, MA: Harvard Educational Review.

Goldstein, H. (2001). Experiential leaming: A foundation for social work education and practice. Alexandria, VA: Council on Social Work Education.

Gollnick, D. M., \& Chinn, P. C. (1994). Multicultural education in a pluralistic society.

Gordon, L. (Ed.). (1983). Homophobia and education: How to deal with name calling. New York: Council on Interracial Books for Children.

Green, J. W. (1999). Cultural awareness in the human services. Boston: Allyn and Bacon.

Helms, J. E. (Ed.). (1990). Black and White racial identity: Theory, research and practice. Westport, CT: Greenwood Press.

Hidalgo, N. M., McDowell, C. L., \& Siddle, E. V. (1990). Facing racism in education. Cambridge, MA: Harvard Educational Review.

Iglehart, A. P. \& Becerra, R. M. (1995). Social services and the ethnic community. Boston: Allyn and Bacon.

Kaplan, R. (Producer \& Director). (1989). Martin Luther King: Legacy of a dream [Video]. (Available from PMI Films Incorporated, $5547 \mathrm{~N}$. Ravenswood Avenue, Chicago, IL 60640)

Kavanagh, K. H., \& Kennedy, P. H. (1992). Promoting cultural diversity: Strategies for health care professionals. Newbury Park, CA: Sage.

Kincheloe, J. L., \& Steinberg, S. R. (1997). Changing multiculturalism. Philadelphia: Open University Press.

King, M. L., Jr. (1990). Letter from a Birmingham jail. In A. O'Gorman, The universe bends toward justice: A reader on Christian nonviolence in the U.S. Philadelphia: New Society Publishers.

Lather, P. (1991). Staying dumb? Student resistance to liberatory curriculum In P. Lather, Getting Smart: Feminist research and pedagogy with/in the postmodem (pp. 123-152). New York: Routledge.

LaVelle, R. (with the staff of Blackside). (1995). America's new war on poverty. San Francisco: KQED Books.

LeDoux, C. \& Montalvo, F. (1999). Multicultural content in social work graduate programs: A national study. Joumal of Multicultural Social Work, 7, 37-55.

Lee, M-Y, \& Gilbert, G. J. (1999). A social constructivist framework for integrating cross-cultural issues in teaching clinical social work. Joumal of Social Work Education, 35(1), 21-37. 
Leigh, J. W. (1998). Communicating for cultural competence. Boston, MA: Allyn \& Bacon.

Lesiak, C. (Producer), \& Jones, M. L. (Co-Producer). (1991). In the White man's image [Video]. (Available from PBS Video, 1320 Braddock Place, Alexandria, VA 22314)

Lewis. E. A. (1995). Continuing the legacy: On the importance of praxis in the education of social work students and teachers. In D. Schoem. L. Frankel. X. Zúñiga, \& E. A. Lewis (Eds.), Multicultural teaching in the university (pp. 26-36). Westport, CT: Praeger.

Lopez, H. I. F. (1998). White by law'. New York: University Press.

Lorde, A. (1984). Sister outsider. Freedom. CA: The Crossing Press.

Lucas, P., Puttkamer, P., von, Tanaka, J. \& Alkali Lake Indian Band (Producers). (1985). Honour of all: Story of Alkali Lake [Video]. (Seattle, WA: Phil Lucas Productions)

Lum, D. (1996). Social work practice \& people of color: A process-stage approach (3rd ed.). Pacific Grove, CA: Brooks/Cole Publishing Company.

Lum, D. (1999). Culturally competent practice. Pacific Grove, CA: Brooks/Cole.

McIntosh, P. (1989, July/August). White privilege: Unpacking the invisible knapsack. Peace and Freedom, 10-12.

McIntosh, P. (1998). White privilege and male privilege: A personal account of coming to see correspondences through work in women's studies. In M. L. Anderson \& P. Hill Collins (Eds.). Race, class, and gender: An anthology (pp. 94-105). Belmont, CA: Wadsworth Publishing Co.

Meyer, C. H. (1994). The latent issues of welfare reform. Affilia, 9, 229-231.

Millstein, K. H. (1997). The taping project: A method for self-evaluation and "informed consciousness" in racism courses. Joumal of Social Work Education, 33, 491-506.

National Association of Social Workers. (1996). NASW code of ethics. Washington, DC: National Association of Social Workers.

Nichols-Casebolt, A., Krysik, J., \& Hermann-Currie, R. (1994). The povertization of women: A global phenomenon. Affilia, 9, 9-29,

Paniagua, F. A. (1994). Assessing and treating culturally diverse clients. A practical guide. Thousand Oaks, CA: Sage.

Pharr, S. (1988). Homophobia: A weapon of sexism (pp. 53-65). Little Rock, AK: Chardon Press.

Pharr, S. (1993). Racist politics and homophobia. Transformation, 8(4), $1-7,10$.

Philleo, J. \& Brisbane, F. L. (1995). Cultural competence for social workers: A guide for alcohol and other drug abuse prevention professionals working with ethnic/racial communities. Washington, DC: Department of Health and Human Services.

Reid, F. (Producer/Director). (1995). Skin deep: College students confront racism [Video]. (Available from California Newsreel, 149 Ninth Street/420, San Francisco, CA 94103.)

Reynolds, A. L. (1995). Challenges and strategies for teaching multicultural counseling courses. In J. G. Ponterotto, J. M. Casas, L. A. Suzuki, \& C. M. Alexander, Handbook of multicultural counseling (pp. 312-330), Thousand Oaks, CA: Sage.

Riggs, M. (Producer/Director) \& Atkinson, N. (Co-Producer). (1995). Black is ... Black ain't [Video]. (Available from California Newsreel, 149 Ninth Street/420, San Francisco, CA 94103)

Ridley, C. R. (1995). Overcoming unintentional racism in counseling and therapy: A practitioner's guide to intentional intervention. Thousand Oaks, CA: Sage Publications.

Roberts, H., Gonzales, J. C., Harris, O. D.. Huff, D. J., Johns, A. M., Lou, R., \& Scott, O. L. (1994). Teaching from a multicultural perspective. Thousand Oaks, CA: Sage.

Rothenberg, P. S. (1998). Race, class, and gender in the United States: An integrated study. New York: St. Martin's Press.

Sands, A. (Producer), \& Banks, D. (Director). (1987). We are family [Video]. (Available from Filmmakers Library, New York)
Schoem, D., Frankel, L., Zúñiga, X, \& Lewis, E. A. (1995). Multicultural teaching in the university. Westport, CT: Praeger.

Scott, D. (1989). Meaning construction and social work practice. Social Service Review, 63, 39-50.

Searle, J. R. (1995). The construction of social reality. New York: The Free Press.

Singh, A. (Producer), \& Roodt, D. J. (Director). (1992). Sarafina [Video]. (Available from Buena Vista Home Video, Department CS, Burbank, CA 91521)

Spielberg, S. (Director), \& Amblin Entertainment (Producer). (1994). Schindler's list [Video]. (Available from MCA Home Video, Inc., 70 Universal City Plaza, Universal City, CA 91608)

The war against woman. (1994, March 28). U.S. New's and World Report, pp. 42-55.

Starrels, M. E., Bould, S., \& Nicholas, L. J. (1994). The feminization of poverty in the United States: Gender, race, ethnicity, and family factors. Joumal of Family Issues, 15, 590-607.

Sue, S. (1994). Introduction. In E. J. Trickett, R. J. Watts, \& D. Birman (Eds.), Human Diversity: Perspectives on people in context (pp. 1-4). San Francisco: Jossey-Bass.

Takaki, R. (1993). A different mirror: A history of multicultural America. Boston: Little, Brown and Company.

Tatum, B. D. (1992). Talking about race, learning about racism: The application of racial identity development theory in the classroom. Harvard Educational Review, 62 (1), 1-24.

Tatum, B. D. (1994). Teaching White students about racism: The search for White allies and the restoration of hope. Teacher's College Record. $95,462-476$.

van Wormer, K. (1994). A society without poverty-The Norwegian experience. Social Work, 39, 324-327.

Winter, S. (1977, winter). Rooting out racism. Issues in Radical Therapy, $17,24-30$

Zinn, H. (1980). A people's history of the United States. New York: Harper Perennial.

Cathryne L. Schmitz is associate professor and director, and Catherine Stakeman is assistant professor, Department of Social Work, University of Southern Maine, Portland, ME 04104. Jose Sisneros is assistant professor, Graduate School of Social Work, University of Denver, 2148 S. High Street, Denver, CO 80208. Cathryne Schmitz can also be reached atcschmitz@usm.maine.edu.

Authors' notes: The authors recognize and thank Virginia Beard for her contribution to this model; without her work the model would not have developed. She devoted her life to the education of our children. Professor Beard struggled to understand how to help students learn the value of diversity and multicultural growth, and she was a great teacher and mentor. Rudy Nickens also provided guidance and modeling in the power of education through the integration of knowledge building with sharing, compassion, and understanding

Based on a paper presented at Emerging Voices of Diversity: Conflict, Consensus, Community, the 1996 AACTE Annual Meeting February 1996 in Chicago, Illinois with Virginia Beard, Department of Education, Saint Louis University.

Manuscript received: February 2, 2000

Revised: November 21, 2000

Accepted: January 8, 2001 